\title{
Stigma Mitigation and the Importance of Redundant Treatments
}

\section{Introduction}

In economics, an increase in risk associated with a task or lottery typically requires an increase in expected payoff if the participant is to remain indifferent between choices (von Neumann and Morgenstern 1947, Savage 1951, Friedman and Savage 1952, Fama and Macbeth 1973, Sharpe 1964). How large the increase in expected payoff must be depends on the individuals' risk preferences and the magnitude of the risk (Tversky and Wakker 1995, Holt and Laury 2002, Harrison et al. 2007). For example, if individuals in an experiment are asked to indicate their willingness to pay (WTP) to avoid drinking a glass of spring water versus a glass of water that has come into contact with a contaminant, one expects the WTP for the contaminated water to be higher because of the potential health risks. How much more an individual would pay should depend on the risk attitudes of the individual and the probability of that person falling ill or even dying. Normative economics suggests that individuals have proportionate responses to increases in participatory risk.

But what if drinking the "contaminated" water does not increase the participatory risk? Say the contaminant is removed and the water treated, so the contaminated water is as clean as the spring water. In that case, its consumption should not increase the individual's WTP relative to spring water. But that may not be the case. Research of psychological stigma has found that individuals can stigmatize perfectly safe items simply because they have previously come into contact with a contaminant. The reason for rejecting a perfectly safe item can be attributed to the notion of "once in contact, always in contact", also referred to as the law of contagion. 
The concept of the law of contagion dates back to the principles of sympathetic magic (see Frazer 1959, Mauss 1972). Although, originally describing primitive and ritualistic belief systems, Rozin et al. (1986) argue that the laws are also present in today's modern Western culture. The principles of sympathetic magic include two laws. (1) The law of contagion, wherein a formerly clean item is stigmatized through contact with a contaminated object, rendering the item itself contaminated. The item remains contaminated even if the item physically is separated from the contaminated object. In this sense, the essence of the contagion remains with the item even when no physical trace is left. One of many real-world examples is recycled drinking water that is, from a scientific perspective, as clean as or even cleaner than other types of drinking water, but is shunned due to its sewage origin. (2) The law of similarity, wherein two objects that resemble one another also share certain properties. For example, chocolate shaped dog feces may drastically reduce an individual's desire to consume the chocolate (Rozin et al. 1986). In this manuscript, our analysis will focus on the stigma related to the first law of sympathetic magic - the law of contagion-and the behavioral responses associated with disgust related to contagion.

Contagion, can stigmatize goods even if the contagion does not increase the participatory risk the contagion may not pose a health risk but, instead, morally offend and disgust individuals, such as a sterile, dead insect dipped into a glass of drinking water. According to Walker (2001) stigma is, “... an unwarranted level of avoidance behavior ... an overreaction to something”. Moreover, although individuals may understand the associated risk from an objective and scientific perspective and may not be fearful, they may still become stigmatized. Their subjective reasoning and the visceral reaction to contaminated items, can be explained by disgust (Fallon et al. 1984, Rozin et al. 1985, Rozin et al. 1986, Nemeroff and Rozin 1994, Flynn et al. 2001, 
Goffman1963, Rozin 2001, Rozin et al. 1995, Hejmadi et al. 2004, Haidt et al. 1994, Rozin et al. 2000). Disgust shares fundamental characteristics with the laws of sympathetic magic and is relatively easy to produce in laboratory settings (Rozin et al. 1986). Moreover, unlike stigma related to bodily harm, such as many technological stigma (see Rozin 2001) disgust offers researchers a safe way to study stigma and stigma mitigation in non-hypothetical experiments. Clearly revealed preference studies, such as exposing participants to bodily harm, are likely unethical and difficult to implement. Thus, making disgust an ideal candidate to study as it invokes a similarly strong stigma response (Rozin 2001).

Oral ingestion ranks among most contaminant-sensitive body spots (Rozin et al. 1995). Additionally, social and cultural norms have a strong influence over disgust (Gerard and Rabbie 1961, Goffman 1963, Kahan 1998, Meigs 1978). In western societies, feces, most body parts and secretions, and insects (especially in North American cultures) are generally considered as disgusting (Rozin et al. 1985). Given the similarities between stigma related to dangerous items and stigma related to disgusting items, we explore behavioral responses in revealed preference experiments related to harmless exposure to a disgusting task. We define disgust, following Rozin et al. (1886), as "a revulsion at the prospect of (oral) incorporation of an offensive substance" (see also Angyal (1941).

An interesting example is drinking water contaminated by a cockroach. In a study in which dead sterilized cockroaches were dipped into glasses of spring water, Rozin et al. (1986) showed principal refusal of participants to drink the water even though there was no increased risk associated with it. These results are important because of their implications for policy and their potentially large monetary effects. However, these conclusions relied on stated preference surveys and, given the hypothetical nature of that research, may not reveal true preferences 
regarding disgust and the cost to overcome it. Rozin et al. (1986) first showed that disgust could be created in the lab by dipping a dead sterilized cockroach into drinking water and recording participants' reactions to the water, offering a unique way to study stigmatization in a risk-free setting. In the same study, the authors showed that experiment participants strongly preferred not to eat pieces of fudge shaped like dog feces or vomit (law of similarity). Moreover, in Rozin (2001) the authors show that orange juice that had been in contact with a dead sterilized cockroach and then frozen for a year still resulted in participants completely rejecting consumption of the juice indicating the time insensitivity of disgust. These experiments were creative and the results interesting; however, given the hypothetical nature of the choices made in the experiments, the results may not be representative of situations in which individuals make incentive-compatible choices - choices in which they receive payment and must actually perform the task. Hence, Rozin et al.'s (1986) findings deserve further exploration.

There exist little research looking at stigma from an economic perspective (Akerlof et al. 1996, O'flaherty and Sethi 2008, Furuya 2002, Vishwanath 1989, Moffitt, 1983, Kanter et al. 2009, Schulze and Wansink 2012, Hoffmann et al. 2014, Wu et al. 2015). Messer et al. (2006), for example showed that stigma maybe time sensitive - in research involving communities that neighbor large superfund sites, when contamination was not removed relatively soon after it occurred, the value of homes surrounding the sites declined even after the point where no human health risks from the contamination remained. Kerley-Keisner et al. (2013) found that when disgust impacts commodities and public goods, group decision-making can foster socially preferred outcomes by alleviating the stigma response. None of the previous literature has adequately addressed the impacts of economic decision-making considering stigmatization through disgust and ways to mitigate these potentially strong reactions. 
Motivated to gain this knowledge and fill the gap in the literature, we conducted experiments with 94 participants in which drinking water was "contaminated" by contact with a dead, sterilized cockroach as in previous studies designed to invoke a stigma response in participants (Rozin et al. 1986). The difference is that our experiments provide monetary incentives. Additionally, we introduce several mitigation steps, wherein we treat the "contaminated" water and compare willingness-to-accept (WTA) responses of participants. This paper makes three primary contributions: (1) We provide an adequate measure of disgust by eliciting WTA responses in incentive compatible experiments - using water contaminated by a dead, sterilized cockroach, thus not increasing the risk associated with drinking it; (2) we explore and provide approaches for reducing disgust and measure the extent of this reduction; and (3) we provide a scale ranking the successful mitigation approaches by the degree of measured mitigation, showing that it may not be the individual stigma mitigation attempt but the combination of multiple steps that can successfully reduce the stigma response of disgust.

\section{Methods}

We collected data on participants' willingness to accept (WTA) payment to drink various types of water. Depending on participants' decisions and a random component, these revealed preferences experiments involved actual exposure to the different types of water, as explained below. Specifically, participants were asked to submit an offer that represented "the lowest amount of compensation they would be willing to accept" to drink each water. We used the Becker-DeGroot-Marschak (BDM) mechanism's (Becker et al. 1964) preference-revealing properties to elicit incentive-compatible WTA data, thus quantifying individual participants' 
values for each type of water. These experiments were IRB-approved and all subjects submitted signed consents before participating. Each participant was paid $\$ 10$ as compensation for their time in addition to the amount they earned in the experiment.

Experimental Sample. In total 96 participants took part in the experiments. Participants consisted of students at Cornell University in the United States. The experiment consisted of four sessions involving two treatments with 24 participants per session. Participants signed up to take part in one of the four sessions and were randomly assigned to one of the two treatments. Additionally, they were randomly assigned to a computer terminals equipped with privacy shields. The first step involved providing instructions (see Appendix A); all were given adequate time to thoroughly review the instructions and then were encouraged to ask questions in case anything about the experiment remained unclear.

In the second step, participants completed a practice session to further acquaint them with the experimental procedure before completing actual experiments. During the practice session, participants had an opportunity to drink as much spring water as they desired at no charge to ensure that they were not thirsty during the second part of the experiment.

Finally, participants completed the high-incentive part of the experiment in which they submitted WTA values for a series of samples of water. After they made their offers for each sample, the experiment administrator determined a random number and compared the participant offers to that number. When an offer was less than or equal to the randomly drawn number, the participant received payment equal to the randomly drawn number and performed the task (drank the water sample). When the offer was greater than the randomly drawn number, the participant received 
no payment and did not perform the task. Recall, these experiments were non-hypothetical and participants were told that deception is not allowed in experimental economics.

Experimental Design. The BDM mechanism has been widely used to elicit WTP and WTA and been shown to produce demand-revealing, incentive-compatible results (Boyce et al. 1992, Irwin et al. 1998, Messer et al. 2010). In our experiments, participants could offer any amount between $\$ 0.00$ and $\$ 30.00$ to drink three ounces of the sample of water. An offer of $\$ 0$ guaranteed payment of at least $\$ 0$ and meant that the participant would definitely drink three ounces of the water. An offer of $\$ 30$ ensured that the participant would not have to drink the water but also meant that no payment would be received. It follows, then, that the highest value participants could offer and still indicate some willingness to drink the water was \$29.99.

In the practice session, all participants were trained in using the BDM mechanism to ensure a thorough understanding of the mechanism and the computer software used to submit offers. During this training, participants were asked to submit an offer representing the least compensation they would accept and still be in favor of a program involving a personal loss of $\$ 2, \$ 5$, or $\$ 8$. Thus, participants were asked to indicate the minimum payment they were willing to accept, in order to lose a certain amount of money. ${ }^{1}$

After completing the training session, participants moved on to the primary part of the experiment. They were asked to make offers on seventeen types of water ${ }^{2}$ subject to two treatments, [T1] and [T2] as indicated:

\footnotetext{
${ }^{1}$ See Appendix A for more details on the practice rounds.

${ }^{2}$ See Appendix B for more details on the types of water.
} 
(1) spring water (SW) [T1, T2],

(2) cockroach water $(\mathrm{CW})[\mathrm{T} 1, \mathrm{~T} 2]$,

(3) boiled (B) cockroach water [T1, T2],

(4) filtered (F) cockroach water [T1, T2],

(5) diluted (D) cockroach water [T1, T2],

(6) tested (T) cockroach water [T1, T2],

(7) boiled, filtered (BF) cockroach water [T1],

(8) filtered, tested (FT) cockroach water [T1]

(9) boiled, diluted (BD) cockroach water [T1],

(10) boiled, tested (BT) cockroach water [T2],

(11) filtered, diluted (FD) cockroach water [T2],

(12) diluted, tested (DT) cockroach water [T2],

(13) filtered, diluted, and tested (FDT) cockroach water [T1],

(14) boiled, filtered, and tested (BFT) cockroach water [T1],

(15) boiled, filtered, and diluted (BFD) cockroach water [T2],

(16) boiled, diluted, and tested (BDT) cockroach water [T2],

(17) boiled, filtered, diluted, and tested (BFDT) cockroach water [T1, T2].

Each of the 96 participants was assigned to one of the four experiment sessions of 24 participants. In each session, the participants made offers on twelve of the seventeen types of water-all submitted offers on types 1 through 6 and on 17; T1 participants made offers on 
types 7 through 9, 13, and 14; and T2 participants made offers on types 10 through 12, 15, and $16 .^{3}$

At the end of the experiment one of the offers was randomly selected for implementation. The participants were randomly assigned to individual computers equipped with privacy shields and Microsoft Excel with Visual Basic to collect their decisions. Note, before participants made their decisions, they received information about each of the water types.

Each water type was presented to participants at the front of the room in labeled containers. All participants witnessed the preparation of all waters, which included the use of a camera at the front of the room, which provided a live-feed to a large screen in the front of the room, ensuring each participant would clearly see the dipping of the cockroach and the mitigation steps. The following example provides a short summary of the experimental instructions (see appendix A) and shows three of the 12 decisions each participant faced. Assume participants $i$ and $j$ make the following three offers ${ }^{4}$ :

Participant $i$ : (1) Spring water: $\$ 0,(2)$ Cockroach water: $\$ 10,(3)$ boiled cockroach water: $\$ 5$.

Participant j: (1) Spring water: \$5, (2) Cockroach water: \$20, (3) boiled cockroach water: \$15.

Outcome determination: After all offers had been submitted by the participants in that session, a volunteer participant drew a numbered ball from a bag and the number on this ball determined the water type (in this example there are three types: spring water, cockroach water and boiled cockroach water). Say, cockroach water is randomly chosen. Next, the compensation for the task

\footnotetext{
${ }^{3}$ The use of two different sets of treatments was due to concerns that posing 17 questions might have been too cognitively difficult for the participants and having too low of a probability of any one decision being selected and result in cash payment.

${ }^{4}$ The actual experiment consisted of 12 decisions each participant made. This simplified example stresses the experimental procedure and shows how the outcome of the experiment was selected.
} 
was determined by having another volunteer participant drop a pen on a random number table $[0.00,29.99]$. Assume the pen drops on $\$ 15.00$. Consequently, participant $i$ receives $\$ 15$ and drinks the cockroach water, because her WTA was smaller than the randomly determined number. Participant $j$, on the other hand, receives no compensation but also does not drink the cockroach water, because her WTA was larger than the randomly determined number.

\section{Results and Discussion}

Descriptive Results. A summary of average WTAs for the different types of water are presented in table 1. We find that participants require $\$ 0.38^{5}$ on average to drink a three-ounce cup of spring water. Most participants (89\%), however, required no compensation to drink spring water. The average WTA for spring water that had been in contact with the cockroach was much higher, $\$ 3.70$, but interestingly, the majority of participants (68\%) still required no compensation to drink it. This result indicates that cockroach-contaminated water does evoke stigma for some people, as indicated by their overreaction to the participatory risk associated with drinking this water. However, the stigma response is far less extreme than indicated in previous studies that relied on hypothetical questioning. In fact, we find that only 13 participants $(14 \%)$ refuse the cockroach-contaminated water as indicated by their WTA of $\$ 30.00$. All other participants are willing to drink it, albeit at a price. When we compare cockroach-contaminated water after a single mitigation step to cockroach-contaminated water, we find that overall WTA drops well below $\$ 3$, with diluting being the lowest at $\$ 2.39$. We conclude, that a single mitigation step may alleviate some but not all of the consumers' concerns about the contamination. Looking at two

\footnotetext{
${ }^{5}$ Please note that these averages are subject to intergroup variation, as single individuals with extreme responses can have substantial impacts on the mean, for example table 1 reports that the overall mean WTA for spring water (S) is $\$ 0.38$. This average consists of the mean WTA from treatment group $1(\$ 0.62)$ and WTA from treatment group 2 (\$0.13).
} 
mitigation steps, three of the six mean WTAs are below $\$ 2$ dollars and two mean WTAs are below offers made for one mitigation step, suggesting that, overall, two mitigation steps may be more effective than one. All mean WTAs were below $\$ 2$ for three and four mitigation steps.

An interesting observation comes from graphical representation of the data in the form of the supply curves presented in Figure 1. In general, supply curves depict the relationship between price and the quantity supplied (WTA at different prices). Figure 1 shows this upward sloping relationship - the higher the price, the more participants are willing to drink the water. Specifically, it shows that effective mitigation may depend not on completion of a single specific type of mitigation measure but instead on completion of multiple mitigation measures. The supply curves depict the percent of participants who would accept each type of water as a function of price (dollar offer). In every case, as the amount paid increases, a greater proportion of the participants is willing to drink the water. For three and four mitigation steps, the supply curves run close together and intertwine, suggesting redundancy associated with adding a fourth mitigation step. Overall, the supply curves highlight another important point—contrary to results previously published using stated-preference experiments that suggested that cockroach contaminated water results in principal refusal by participants—our results suggest that there is a price at which the stigma can be overcome. This result is interesting from at least two different perspectives. The first perspective is a psychological one, wherein the first law of sympathetic magic states that the contaminated water would remain contaminated and mitigation may be impossible or very difficult. The second perspective is an economic one, wherein participants should not require additional compensation considering the additional risk associated with drinking the contaminated water. 
Regression Results. To generate WTA estimates and account for truncation at $\$ 0$ and $\$ 30$, we used a two-limit random-effect Tobit regression model. Each participant submitted twelve offers (one for each type of water presented). However, when considering both treatments, there were seventeen offers. The dependent variable was the value $(V)$ representing each participant's offer. Dummy variables were introduced to indicate the specific type of water while spring water $(S)$ was omitted. Additionally, we included dummy variables to control for gender and age effects. The model can be summarized by a mathematical formulation for person $i$ :

$V_{i j}=\alpha+\beta_{1} * C_{i j}+\beta_{2} * B_{i j}+\beta_{3} * F_{i j}+\beta_{4} * D_{i j}+\ldots+\beta_{17} * B F D T_{i j}+\beta_{18} *$ Female $_{i j}+\beta_{19} * A g e_{i j}+\mu_{i}+\varepsilon_{i}$

where $\mu_{i} \sim \mathrm{N}\left(0, \sigma_{\mu}^{2}\right)$ and $\varepsilon_{i j} \sim \mathrm{N}\left(0, \sigma^{2}\right)$.

Table 2 shows the results of this model. Participants required significantly more money to drink the cockroach-contaminated water relative to the spring water - this difference is significant at the $1 \%$ level. Furthermore, the analysis shows that participants, on average, also required a significantly greater payment to drink contaminated water that had undergone one mitigation step relative to spring water.

Although larger payments were required for cockroach-contaminated water that had undergone two mitigation steps (with the exception of DF), overall some significance is lost; the increase in payment required for FT and DT water was significant at the 5\% level and no significant difference between DF and spring water was found. In the case of three mitigation steps, participants required significantly more money (relative to spring water) only for BDT. After four mitigation measures, participants did not require significantly greater payment to drink the treated water compared to spring water. These results supported our observation from the supply 
curves that stigma is reduced not by one particular type of mitigation step but by a more comprehensive, multi-step approach.

We used a Wald test to determine whether the regression coefficients for each number of mitigation steps are equal to each other. In case the test fails to reject the null-hypothesis, it suggests that removing the variables from the regression model will not harm the overall fit of the Tobit regression model. The following three hypotheses were tested:

One mitigation step, $H_{0}: B=F=D=T$

Two mitigation steps, $H_{0}: B F=F T=B D=B T=D F=D T$

Three mitigation steps, $H_{0}: B F D=B D T=F D T=B F T$

Based on the Wald test, we cannot reject any of the null hypothesis that the coefficients in each mitigation-step group are equal to each other. Therefore, inclusion of each individual mitigation step may not improve the overall fit of the model. The associated $p$-values are 0.32 for one mitigation step, 0.56 for two mitigation steps, and 0.74 for three mitigation steps. While the Wald test confirms our previous conjecture in that there are no significant differences between the coefficients for the three groups, it does not provide information about any redundancy of mitigation steps.

To identify the most effective combinations of steps, we added one more regression (see table 3 ). In this model, we introduced dummy variables to indicate the number of mitigation steps rather than water type. Once again, spring water was omitted and gender and age dummies are included. The two-limit random-effect Tobit model for person $i$ can be summarized as 
$V_{i j}=\alpha+\beta_{1} *$ mitigate $_{i j}+\beta_{2} *$ 2mitigate $_{i j}+\ldots+\beta_{4} * 4$ mitigate $_{i j}+\beta_{5} *$ Female $_{i j}+\beta_{6} *$ Age $_{i j}+\mu_{i}+\varepsilon_{i}$

where $\mu_{i} \sim \mathrm{N}\left(0, \sigma_{\mu}^{2}\right)$ and $\varepsilon_{i j} \sim \mathrm{N}\left(0, \sigma^{2}\right)$.

This regression shows that nearly all of the coefficients are positive and significant at the $1 \%$ level, indicating that participants required significantly greater compensation to be willing to drink the contaminated water and treated waters relative to spring water. To determine whether the regression coefficients for the same number of mitigation are equal to each other and, thus, do not add significant explanatory power to the overall model, we ran three more Wald tests:

One $\&$ two mitigation steps, $H_{0}$ : 1mitigate $=2$ mitigate

Two \& three mitigation steps, $H_{0}:$ 2mitigate $=3$ mitigate

Three $\&$ four mitigation steps, $H_{0}:$ 3mitigate $=4$ mitigate

This time, we can reject the null hypothesis for two of the three joint effects, indicating that the coefficients for one and two mitigation steps are not all the same $(p=0.0118)$ and, therefore, significantly improve the fit of the model. The same holds true for two and three mitigation steps ( $p=0.006)$, thus, including both explanatory variables improves the fit of the model. The Wald test for three and four mitigation steps, on the other hand, is not significant $(p=0.697)$ so there is no further significant improvement achieved by including four water treatments. In order to understand the full relevance of these findings, we have to consider the Tobit regression (equation 2) in combination with the following Wald tests. The Tobit results show declining coefficients - "Cockroach" = 17.4774, "One Mitigation Step" = 14.2290, "Two Mitigation Steps" = 11.7147, "Three Mitigation Steps" = 9.6869 and "Four Mitigation Steps" = 9.2971 This shows us that participants' WTA declines with the more mitigation steps the cockroach 
water undergoes. The Wald tests show that there are significant differences between the coefficients, except "Three Mitigation Steps" and "Four Mitigation Steps". In other words, the Tobit results show the reductions in WTA, while the Wald test show that the coefficients are significantly different from one another. We find that each additional mitigation step significantly reduces the WTA up to three mitigation steps, but adding a forth mitigation steps does not significantly reduce the WTA.

This result further bolsters our finding that successful treatment of cockroach-contaminated water depends on the number of mitigation steps applied rather than on the specific mitigation measure used-two treatments are better than one and three are better than two, but a fourth treatment provides no significant improvement. This also is shown by the rightward-shifting supply curves in Figure 1, which start with cockroach-contaminated water on the far left and move ever closer to spring water on the far right with the curves for three and four mitigation steps intertwined.

The results of these experiments make three important contributions in addressing our research objectives: First, they provide an adequate measure of disgust associated with water contamination without increasing the risk to participants from drinking the modified water. We developed a measure of disgust in a laboratory setting by eliciting participants' WTA drinking cockroach-contaminated water. Most participants reacted rationally to this risk-free choice by offering zero dollars. Few participants overreacted to the cockroach-contaminated water and refused to drink it. Hence, on average, we did not find refusal to drink contaminated water; instead, we showed how much compensation was required for participants to drink water that might be deemed disgusting. These results show are stark deviations from previous, hypothetical, findings that suggest participants reject water contaminated by a dead sterilized cockroach. 
Given the behavioral similarities between disgust and other stigmatizing tasks and items, such as technological stigma (Rozin 2001), our results may provide a broader insight into the intersection of psychology and economics.

Second, our experiments explore possibilities that may reduce disgust and measure the reduction. Our results suggest that treating water mitigation measures can reduce the disgust experienced by participants. And up to a point, combining multiple steps is even more effective. Moreover, we show that these reductions in WTA are significant and can be achieved by relatively simple and inexpensive mitigation measures such as extra filters and boiling the water.

Our third objective was to rank successful mitigation approaches by the degree of stigma reduction. Our results show that combining several simple mitigation measures may adequately reduce individual perceptions of disgust associated with once-contaminated water. Although single mitigation steps reduce WTA, it may not matter which single step is performed. A more comprehensive approach of combining three or four measures proved to be the most effective in reducing disgust. With three measures being just as effective as four measures, making the additional fourth measure redundant. These result further supports the notion that simple, inexpensive mitigation measures can be effective in diminishing the stigma associated with objectively safe but subjectively disgusting tasks and items.

\section{Conclusion}

In this research, we provide a monetary measurement of disgust using participants' willingness to accept monetary compensation to consume various types of treated and untreated "contaminated" water, allowing us to put a price on stigma associated with disgust. We show that the stigma can be successfully mitigated by four treatments of water (filtering, boiling, 
diluting, and testing), reducing participants' overreaction to the risk of consuming the water. Interestingly, although each mitigation measure individually reduced WTA, none was significantly more successful than another. Specifically, we find no significant difference between all one-step, two-step, three-step, and four-step mitigation efforts. Consequently, it may not be the individual mitigation method (boiling, filtering, diluting or testing) that mitigates stigma successfully but the combination of steps. Following this conjecture, we find significant differences for combinations of mitigation measures. Two-step approaches were more successful than one-step approaches, and three- and four-step approaches were more successful than twostep approaches. Adding a fourth step did not induce a significant reduction over three steps. These results clearly demonstrate the range in which mitigation is most effective and the importance of redundant treatments.

Our study also demonstrates the differences between previous hypothetical, questioning concerning behaviors related to disgust. We show that when participants make incentivecompatible choices in experiments involving monetary incentives, disgust related to stigmatizing behavior may have been overstated in previous studies. Additionally, we find that relatively simple and cheap mitigation can be successful in reducing disgust.

Our study of contaminated water samples allowed us to study disgust and shares fundamental properties with studies of stigma related to fear of increased risk associated with a task, item, or technology. Additionally, the concept of disgust offers experimenters a way to research responses safely, avoiding ethical dilemmas related to settings and tasks that can induce fear and expose participants to adverse health effects. We note that extrapolation of these results beyond water contamination may be difficult since individual stigmas present unique levels of disgust and sometimes of danger that depend on social and cultural norms and the amount of risk 
involved. Therefore, we encourage further studies to shed additional light on the complex phenomenon of stigma. In addition, some stigmas may be difficult or even impossible to study experimentally, largely because of ethical boundaries related to studying risk in an environment, such as the experimental economics laboratory, that traditionally does not permit deception. For this reason, situations that provoke disgust rather than being actually dangerous are ideal for studying stigma and its mitigation.

\section{ACKNOWLEDGEMENTS}

The research was supported by funding from the National Science Foundation (EPS-1301765 and DRMS-0551289). We are also grateful to Julie Grossman for her help preparing the materials used in this research. 


\section{REFERENCES}

Akerlof, G. A., J.L. Yellen, and M.L. Katz. 1996. An analysis of out-of-wedlock childbearing in the United States. The Quarterly Journal of Economics, 277-317.

Angyal, A. 1941. "Disgust and related aversions." The Journal of Abnormal and Social Psychology 36(3): 393-412.

Becker, G. M, M. H. DeGroot, and J. Marschak. 1964. "Measuring Utility by a Single-Response Sequential Method.” Behavioral Science 9(3): 226-232.

Boyce, R. R., T. C. Brown, G. H. McClelland, G. L. Peterson, and W. D. Schulze. 1992. “An Experimental Examination of Intrinsic Values as a Source of the WTA-WTP Disparity." American Economic Review 82(5): 1366-1373.

de França Doria, Miguel. 2010. "Factors influencing public perception of drinking water quality." Water policy 12 (1) 1-19.

Fallon, A. E., P. Rozin, and P. Pliner. 1984. "The Child's Conception of Food: the Development of Food Rejections with Special Reference to Disgust and Contamination Sensitivity." Child Development 55(2): 566-575.

Fama, E. F., and Macbeth, J. D. (1973). Risk, return, and equilibrium: Empirical tests. The Journal of Political Economy, 607-636.

Flynn, J., P. Slovic, and H. Kunreuther, eds. 2001. Risk, Media, and Stigma: Understanding Public Challenges to Modern Science and Technology Sterling, VA: Earthscan Publication Ltd.

Frazer, J. G. (1959). The new golden bough: A study in magic and religion (abridged). New York: Macmillan (Edited by T.H. Caster, 1922; Original work published 1890).

Friedman, M., and Savage, L. J. (1952). The expected-utility hypothesis and the measurability of utility. The Journal of Political Economy, 463-474.

Furuya, K. (2002). A socio-economic model of stigma and related social problems. Journal of economic behavior \& organization, 48(3), 281-290.

Gerard, H. B., and Rabbie, J. M. (1961). Fear and social comparison. The Journal of Abnormal and Social Psychology, 62(3), 586.

Gleick, Peter H., and Meena Palaniappan. 2010. "Peak water limits to freshwater withdrawal and use." Proceedings of the National Academy of Sciences 107 (25) 11155-11162.

Goffman, E. 1963. Stigma: Notes on the management of spoiled identity. Englewood Cliffs, NJ: Prentice-Hall. 
Haidt, J., C. McCauley, and P. Rozin. 1994. "Individual differences in sensitivity to disgust: A scale sampling seven domains of disgust elicitors." Personality \& Individual Differences 16(5): 701-713.

Harrison, G. W., Lau, M. I., \& Rutström, E. E. (2007). Estimating risk attitudes in Denmark: A field experiment*. The Scandinavian Journal of Economics, 109(2), 341-368.

Hejmadi, A, P. Rozin, and M. Siegal. 2004. "Once in Contact, Always in Contact: Contagious Essence and Conceptions of Purification in American and Hindu Indian Children." Developmental Psychology 40(4): 467-476.

Hoffmann, V., J.R. Fooks, and K.D. Messer. 2014. Measuring and Mitigating HIV Stigma: A Framed Field Experiment. Economic Development and Cultural Change, 62(4), 701-726.

Holt, C. A., \& Laury, S. K. (2002). Risk aversion and incentive effects. American economic review, 92(5), 1644-1655.

Immerzeel, W. W., Van Beek, L. P., \& Bierkens, M. F. (2010). Climate change will affect the Asian water towers. Science, 328(5984), 1382-1385.

Irwin, J. R., G. H. McClelland, M. McKee, W. D. Schulze, and N. E. Norden. 1998. "Payoff Dominance vs. Cognitive Transparency in Decision Making.” Economic Inquiry 36(2): $272-285$.

Ishida, J. (2003). The role of social norms in a model of marriage and divorce. Journal of economic behavior \& organization, 51(1), 131-142.

Kahan, D. M. 1998. "The Anatomy of Disgust” in Criminal Law. Michigan Law Review 96 (6) 1621-1657.

Kerley-Keisner, D. K., K.D. Messer, W.D. Schulze, and H. Zarghamee. 2013. Testing Social Preferences for an Economic "Bad": An Artefactual Field Experiment*. The Scandinavian Journal of Economics, 115(1), 27-61.

Meigs, A. S. (1978). A Papuan perspective on pollution. Man, 304-318.

Mauss, M. (1972). A general theory of magic. (Robert Brain, Trans.). New York: W. W. Norton. (Original work published 1902).

Messer, K. D., G.L. Poe, D. Rondeau, W.D. Schulze, and C.A. Vossler. 2010. Social preferences and voting: An exploration using a novel preference revealing mechanism. Journal of Public Economics, 94(3), 308-317.

Messer, K. D., Schulze, W. D., Hackett, K. F., Cameron, T. A., and McClelland, G. H. (2006). Can stigma explain large property value losses? The psychology and economics of Superfund. Environmental and Resource Economics, 33(3), 299-324. 
Moffitt, R. (1983). An economic model of welfare stigma. The American Economic Review, 1023-1035.

Nemeroff, C. and P. Rozin. 1994. "The Contagion Concept in Adult Thinking in the United States: Transmission of Germs and of Interpersonal Influence.” Ethos 22(2): 158-186.

O'Flaherty, B. and R. Sethi. 2008. Racial stereotypes and robbery. Journal of Economic Behavior \& Organization, 68(3), 511-524.

Po, M., Kaercher, J.D., Nancarrow, B.E., 2003. Literature Review of Factors Influencing Public Perceptions of Water Reuse. CSIRO Land and Water Technical Report. CSIRO.

Postel, Sandra L., Gretchen C. Daily, and Paul R. Ehrlich. "Human appropriation of renewable fresh water." Science, 271 (5250) 785-787.

Ross, V. L., Fielding, K. S., \& Louis, W. R. (2014). Social trust, risk perceptions and public acceptance of recycled water: Testing a social-psychological model. Journal of environmental management, 137, 61-68.

Rozin, P. 2001. "Technological Stigma: Some Perspectives from the Study of Contagion,” in Risk, Media, and Stigma: Understanding Public Challenges to Modern Science and Technology, Eds. J. Flynn, P. Slovic and H. Kunreuther, pp. 31-40. Sterling, VA: Earthscan Publication Ltd.

Rozin, P., A. Fallon, and M. Augustoni-Ziskind. 1985. "The Child's Conception of Food Contamination Sensitivity to "Disgusting" Substances." Developmental Psychology 21(6): 1075-1079.

Rozin, P., C. Nemeroff, M. Horowitz, B. Gordon, and W. Voet. 1995. "The Borders of the Self: Contamination Sensitivity and Potency of the Body Apertures and Other Body Parts." Journal of Research in Personality 29(3): 318-340.

Rozin, P., J. Haidt, and C. McCauley. 2000. "Disgust," in Handbook of Emotions $2^{\text {nd }}$ edition, Eds. M. Lewis and J. Haviland, pp. 637-653. New York, NY: Guilford Press.

Rozin, P., L. Millman, and C. Nemeroff. 1986. "Operation of the Laws of Sympathetic Magic in Disgust and Other Domains.” Journal of Personality and Social Psychology 50(4): 703712.

Savage, L. J. (1951). The theory of statistical decision. Journal of the American Statistical association, 46(253), 55-67.

Schulze, W., and B. Wansink. 2012. "Toxics, Toyotas, and terrorism: the behavioral economics of fear and stigma." Risk Analysis 32, no. 4: 678-694.

Sharpe, W. F. (1964). Capital asset prices: A theory of market equilibrium under conditions of risk. The journal of finance, 19(3), 425-442. 
Tversky, A., \& Wakker, P. (1995). Risk attitudes and decision weights. Econometrica: Journal of the Econometric Society, 1255-1280.

Uhlmann, V., \& Head, B. (2011). Water recycling: recent history of local government initiatives in South East Queensland. Urban Water Security Research Alliance.

United Nations. 2010. The right to water. Accessed on April 02, 2015 at: http://www.ohchr.org/Documents/Publications/FactSheet35en.pdf.

Vishwanath, T. (1989). Job search, stigma effect, and escape rate from unemployment. Journal of Labor Economics, $\mathrm{v}$ 487-502.

Von Neumann, J., \& Morgenstern, O. 1947. Theory of games and economic behavior (2d ed. Princeton, NJ: Princeton.

Vörösmarty, C. J., Green, P., Salisbury, J., \& Lammers, R. B. (2000). Global water resources: vulnerability from climate change and population growth. Science, 289(5477), 284-288.

Walker, V. 2001. "Defining and Identifying 'Stigma"' in Risk, Media, and Stigma: Understanding Public Challenges to Modern Science and Technology, Eds. J. Flynn, P. Slovic and H. Kunreuther, pp. 175-185. Sterling, VA: Earthscan Publication Ltd.

Wu, S., J. Fooks, K.D. Messer, and D. Delaney. 2015. "Consumer Demand for Local Honey." Applied Economics. 47(14): 4377-4394. 


\begin{tabular}{cccc}
\hline \multicolumn{4}{c}{ Table 1. Averages by Treatment } \\
\hline \hline & $\begin{array}{c}\text { WTA } \\
\text { (T1\&T2) }\end{array}$ & $\begin{array}{c}\text { WTA } \\
(\mathrm{T} 1)\end{array}$ & $\begin{array}{c}\text { WTA } \\
(\mathrm{T} 2)\end{array}$ \\
\hline S & $\$ 0.38$ & $\$ 0.62$ & $\$ 0.13$ \\
$\mathrm{C}$ & $\$ 3.70$ & $\$ 3.04$ & $\$ 4.35$ \\
$\mathrm{~B}$ & $\$ 2.76$ & $\$ 2.25$ & $\$ 3.27$ \\
F & $\$ 2.72$ & $\$ 2.58$ & $\$ 2.87$ \\
D & $\$ 2.39$ & $\$ 2.15$ & $\$ 2.63$ \\
T & $\$ 2.38$ & $\$ 2.41$ & $\$ 2.34$ \\
\hline BF (T1) & & $\$ 1.83$ & \\
FT (T1) & & $\$ 2.17$ & \\
BD (T1) & & $\$ 1.56$ & \\
\hline BT (T2) & & & $\$ 3.20$ \\
DF (T2) & & & $\$ 2.25$ \\
DT (T2) & & & $\$ 1.71$ \\
\hline BFD (T1) & & $\$ 1.59$ & \\
BDT (T1) & & & $\$ 1.52$ \\
\hline FDT (T2) & & & $\$ 1.21$ \\
BFT (T2) & & & \\
\hline BFDT & $\$ 1.50$ & $\$ 1.51$ & $\$ 1.50$ \\
\hline N
\end{tabular}

Notes: All participants submitted 12 WTA offers. All participants submitted offers for all single mitigation steps and the combination of all four mitigation steps. Additionally, participants submitted three offers for two mitigation steps and two offers for three mitigation steps (between-subjects). 


\begin{tabular}{ccccc}
\hline Table 2: Two-Limit Random Effects Tobit Regression Results & & \\
\hline \hline & & Coefficient & Standard Error & p-Value \\
\cline { 2 - 5 } Contamination & Cockroach & 17.3197 & 6.6773 & 0.009 \\
\hline \multirow{3}{*}{ One Mitigation } & Boiled & 14.8971 & 4.4061 & 0.001 \\
Step & Diltered & 14.2044 & 6.5965 & 0.031 \\
& Tested & 14.0335 & 4.1204 & 0.001 \\
& Boiled\&Filtered & 13.4406 & 6.5677 & 0.041 \\
\hline Filtered\&Tested & 12.6159 & 4.8630 & 0.009 \\
Two Mitigation & Boiled\&Dilluted & 13.9620 & 7.3632 & 0.058 \\
Steps & Boiled\&Tested & 13.9754 & 4.6899 & 0.011 \\
& Dilluted\&Filtered & 9.2128 & 5.6161 & 0.018 \\
& Dilluted\&Tested & 8.1682 & 4.1574 & 0.198 \\
Three Mitigation & Boiled\&Filtered\&Dilluted & 11.7806 & 7.0759 & 0.099 \\
Steps & Boiled\&Dilluted\&Tested & 11.9031 & 4.6933 & 0.096 \\
& Filter\&Dilluted\&Tested & 7.7138 & 6.8841 & 0.011 \\
Boiled\&Filtered\&Tested & 6.3782 & 4.4650 & 0.153 \\
\hline \multirow{2}{*}{ Four Mitigation } & Boiled\&Filtered\&Dilluted\&Tested & 3.8637 & 4.5547 & 0.396 \\
Steps & Female & 3.8637 & 4.5547 & 0.396 \\
& Age & -5.1440 & 3.5324 & 0.145 \\
\hline \multirow{4}{*}{ Constant } & 64.6090 & 64.5052 & 0.317 \\
\hline
\end{tabular}

Notes: $\mathrm{N}=1128$, left-censored observations $=835$, uncensored observations $=252$, right-censored observations $=41$.

(94 choices for S, C, F, D, B, T, FDBT; 47 Choices for BF, FT, BD, BFD, BDT; 47 choices for BT, DF, DT, FDT, BFT). 


\begin{tabular}{cccc}
\hline Table 3: Two-Limit Random Effects Tobit Regression Results per Mitigation Steps & \\
\cline { 2 - 4 } Cockroach & Coefficient & Standard Error & p-Value \\
\cline { 2 - 4 } One Mitigation Step & 17.4774 & 4.2481 & 0.000 \\
Two Mitigation Steps & 14.2290 & 3.7664 & 0.000 \\
Three Mitigation Steps & 11.7147 & 3.3860 & 0.001 \\
Four Mitigation Steps & 9.6869 & 3.0810 & 0.002 \\
Female & 9.2971 & 3.2208 & 0.004 \\
Age & 3.6412 & 4.9059 & 0.458 \\
Constant & -4.9180 & 3.3126 & 0.138 \\
\hline
\end{tabular}

Notes: $\mathrm{N}=1128$

564 choices for one mitigation step; 282 choices for two mitigation steps; 282 choices for two mitigation steps;

188 choices for three mitigation steps; 94 choices for four mitigation steps. 
Figure 1: Supply Curves Generated from WTA Data.

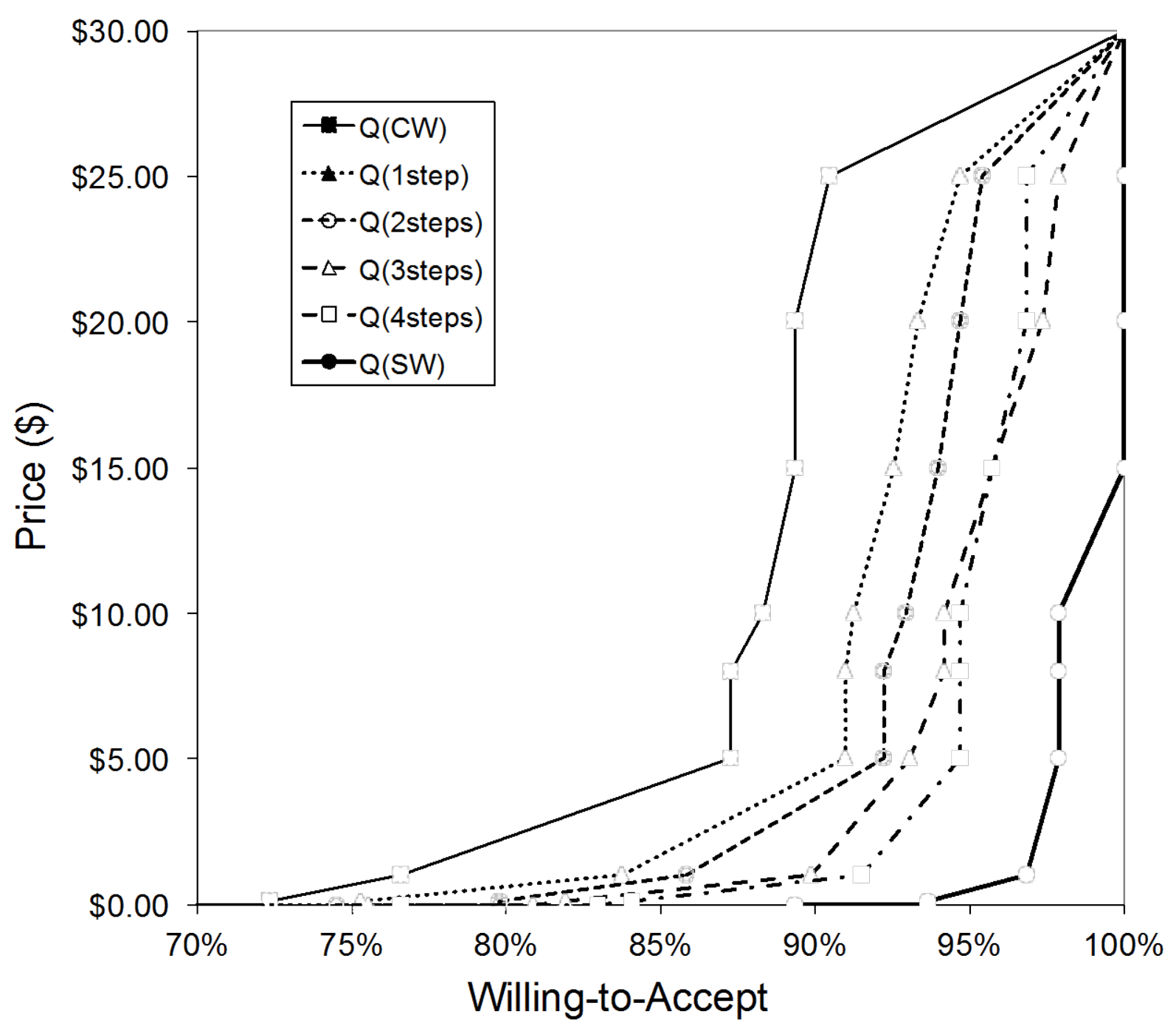

